\title{
Organizational Adaptation to Changing Environments
}

\author{
Community Mental Health \\ and Drug Abuse Services
}

\section{THOMAS D'AUNNO}

RICHARD H. PRICE

University of Michigan

Our primary purpose in this article is to describe a conceptual approach to research on mental health organizations that we believe may be useful for social scientists and policymakers interested in understanding and improving mental health services. To illustrate the conceptual approach, we will describe briefly a study of community mental health centers that we are currently conducting at the Institute for Social Research, University of Michigan. In effect, this article presents a case study of one approach te research on mental health organizations.

\section{CONCEPTUAL FRAMEWORK AND ASSUMPTIONS}

The conceptual framework for our research, depicted in Table 1 , rests on a set of assumptions concerning (1) the environment of mental health organizations, (2) organizational response or adaptation to the environment, and (3) client-organization relationships. These are discussed in some detail in this section.

\footnotetext{
Author's Note: Preparation of this article was supported in part by Grant R01 DA03272 from the National Institute for Drug Abuse and by a contract fromthe National Institute of Mental Health.
}

AMERICAN BEHAVIGRAL SCIENTIST, YoL 28 No. 5, May/June 1985 669-683

- 1985 Sage Publications, Inc. 
TABLE 1

A Conceptual Framework for the Study of Mental Health

Organizations: Key Assumptions

\begin{tabular}{|c|c|c|}
\hline $\begin{array}{l}\text { Organization } \\
\text { Environment }\end{array}$ & Organizational Adaptation & $\begin{array}{c}\text { Client-Organization } \\
\text { Relations }\end{array}$ \\
\hline $\begin{array}{l}\text { Environment determines, } \\
\text { to a large extent, the } \\
\text { structure, technology, } \\
\text { and ideology of organ- } \\
\text { izations }\end{array}$ & $\begin{array}{l}\text { Response to demands from } \\
\text { the environment requires } \\
\text { changes in organization } \\
\text { structures, technology, } \\
\text { and ideology }\end{array}$ & $\begin{array}{l}\text { Clients are relatively } \\
\text { dependent on organi- } \\
\text { tions }\end{array}$ \\
\hline $\begin{array}{l}\text { Actors control key } \\
\text { resources including } \\
\text { legitimacy, societal } \\
\text { support, and } \\
\text { funding }\end{array}$ & $\begin{array}{l}\text { Organizations fail to adapt } \\
\text { due to "bounded ration- } \\
\text { ality"-i.e., limitations } \\
\text { of information processing } \\
\text { and perceputal mecha- } \\
\text { nisms-and because they } \\
\text { lack required resources } \\
\text { or cannot mobilize them } \\
\text { quickly enough }\end{array}$ & $\begin{array}{l}\text { Client relationships with } \\
\text { organizations unfold } \\
\text { in "career" including } \\
\text { entry, diagnosis, } \\
\text { assessment, treatment, } \\
\text { and exit }\end{array}$ \\
\hline $\begin{array}{l}\text { Relations among actors } \\
\text { in the environment } \\
\text { are complex (and } \\
\text { often hierarchical) }\end{array}$ & & $\begin{array}{l}\text { Client career is heavily } \\
\text { influenced by the } \\
\text { nature of organiza- } \\
\text { tional adaptation }\end{array}$ \\
\hline
\end{tabular}

\section{THE ENVIRONMENTS OF MENTAL HEALTH ORGANIZATIONS}

The first, and perhaps most important, assumption in our framework is that the environment of mental health organizations determines, to a significant extent, their structure and operations. Of course, we are not alone in placing emphasis on the role of the environment in shaping organizational behavior. The relationship between organizations and their environments has drawn steadily increasing attention from organizational theorists over the last two decades. In fact, there now exist several approaches for analyzing organization-environment relations. Such approaches include the following: the resource dependence perspective (Pfeffer \& Salancik, 1978); the transaction cost or markets and hierarchies perspective (Williamson, 1981; Williamson and Ouchi, 1981); the political economy model (Hasenfeld, 1972; Wamsley and Zald, 1976); network analysis (Aldrich, 1979; Burt, 1980; Cook, 1977); the natural selection or population ecology perspective (Aldrich, 1979; Hannan and Freeman, 1977, 1984; McKelvey and Aldrich, 1983); interorganizational field analysis (Warren, 1967); the organization set 
approach (Evan, 1966); and, more recently, an approach that defines the environment of organizations in terms of societal sectors with distinctive social and cultural characteristics (Meyer and Rowan, 1977; Meyer and Scott, 1983).

These approaches vary in at least three ways. First, the approaches differ with respect to level of analysis: some are concerned primarily with relations between a focal organization and other organizations with which it interacts (e.g., organization set approach) while other approaches focus on the larger social context in which organizations are embedded. Indeed, the natural selection perspective focuses on entire "populations" of organizations. Second, the approaches differ in their views of the extent to which organizations can respond to threats and opportunities in their environment. On the one hand, for example, the population ecology perspective asserts that individual organizations are relatively unable to adapt to environmental contingencies. In contrast, the resources dependence perspective assumes that managers can, and do, manipulate environments to counteract threats and take advantage of opportunities.

Third, the approaches differ in their conceptual definition of "organization environment," and, as a consequence, they tend to focus on different substantive aspects of "environments" (see Hall, 1977). As Scott (1983) points out, early work focused on the technical aspects of environments - that is, environments were viewed as pools of resources or information required to perform work. More recently, and in contrast to previous emphases on the technological environment of organizations, Meyer and Scott (1983) and others have turned attention to the social and cultural environments of organizations and the norms and authority structures that characterize them.

Of course, the issues of level of analysis, potential for organizational adaptation, and conceptual and substantive focus are not unrelated. It seems, for example, that conceptual perspectives on organizationenvironment relations that are concerned with higher levels of analysis (e.g., societal) are less likely to assume that organizations can adapt to their environments. Similarly, analyses that emphasize the social and cultural aspects of environments are more likely (almost by definition) to focus on higher levels of analysis.

Our conceptual framework draws on many of the perspectives noted above, modifying some of their assumptions. We believe that the environment of mental health organizations can be usefully viewed from the vantage point of multiple levels of analysis, including societal, community, network, and organizational dyads. Further, we assume 
that, for the most part, forces and actors at the more inclusive or higher levels of analysis exert influence on actors at lower levels of analysis. In other words, local mental health organizations are heavily influenced by state agencies, which themselves are influenced by federal or national policies and organizations.

However, we do not assume that the behavior of individual organizations is completely determined by their environment. Rather, we assume that organizations can, and do, adapt to contingencies in the environment, for example, with strategies such as joint ventures, mergers, and coalition building (Pfeffer and Salancik, 1978). As Hasenfeld (1983) points out, such strategies produce a pattern of interorganizational relations that are not necessarily rational and effective from the clients' or consumers' standpoint: "The network of services is likely to be characterized by redundancy together with major service gaps; limited cooperation and contradictory or inconsistent service delivery patterns; and multiple interorganizational links and contracts but no overall rational and effective service network" (1983: 83). What is needed is research that begins to develop typologies of mental health organizations and links organizational types to the use of various adaptive strategies or to the inability to adapt (McKelvey and Aldrich, 1983; Hasenfeld, 1983).

To clarify and develop our definition of the environment some additional points should be emphasized. First, although we define the environment of mental health organizations rather broadly, we assume that not all the actors with which a given mental health organization (or population of organizations) interacts, or could interact, are of equal importance. On the contrary, the importance of particular actors to mental health organizations increases to the extent that the actors (or a given actor) control valued resources, and such resources are difficult to obtain from other sources. That is, the salience of actors in the environment of organizations is a function of resource dependence (Emerson, 1962; Blau, 1964; Thompson, 1967; Hasenfeld, 1972; Jacobs, 1974; Pfeffer and Salancik, 1978). More specifically, mental health organizations require resources such as legitimacy, authority, funds, personnel, and clients to perform work and to survive. Thus, they are forced into relationships with a variety of actors to obtain needed and valued resources. Further, we assume (cf. Meyer and Scott, 1983) that not all resources are of equal importance to mental health organizations.

In our view, the most important resources, and hence actors, for mental health organizations are those that provide them with legitimacy 
and societal support. The actors that provide legitimacy for mental health organizations include regulatory, licensing, and accreditation bodies as well as local, state, and federal legislatures and offices. These groups and organizations have the societal authority to mandate the existence of mental health organizations. Funding for mental health services through third-party reimbursement or government grants is contingent on their serving roles that are legitimized by societal institutions.

Moreover, as others have pointed out (Warren, 1972; Meyer and Scott, 1983) the actors that provide legitimacy and other key resources for mental health organizations often are connected to each other in complex and hierarchical ways. We assume it is important to map the linkages among organizations and groups in the environment of mental health organizations. For example, various accreditation and licensing agencies may be tightly linked and, as a consequence, their requirements for mental health organizations may be quite similar.

In this section, we have defined the environment of mental health organizations broadly as a set of actors who possess valued resources, particularly legitimacy and societal support - prerequisites for funding and clients - that mental health organizations need to perform work and survive. These actors are connected to each other in complex ways, demanding that we examine the environment from multiple levels of analysis, including societal, community, and organizational levels.

The mechanism by which actors in the environment influence mental health organizations is resource dependence: Organizations generally conform to the rules, norms, and requirements of actors on whom they depend for valued resources. Of course, decision makers in mental health organizations are hampered by bounded rationality (March and Simon, 1958) and other limitations, and, as a consequence, they do not always respond to demands from the environment. On the other hand, many individual organizations do adapt to environmental contingencies, employing a variety of strategies. Thus, we adopt a position of less than strict environmental determinism. In the next section, we discuss our assumptions concerning the adaptation of mental health organizations in more detail.

\section{THE ADAPTATION OF MENTAL HEALTH ORGANIZATIONS}

We define "organizational adaptation" as changes in structure, technology, and ideology that organizations make in response to environmental demands and opportunities. As discussed above, mental 
health organizations depend heavily on a variety of actors in their environment and, as a result, the task of adaptation is difficult. We do not mean to imply, however, that mental health organizations are constantly adapting to their environment. In many instances their environments may remain stable and require little adaptation. Indeed, as Hannan and Freeman (1984) suggest, it may be the timing or temporal pattern of changes in environmental demands that determine successful organizational adaptation.

\section{Changes in Structure, Technology, and Ideology}

An important assumption in our framework is that adaptation to environmental demands often requires nontrivial, relatively enduring changes in the structure, technology, and ideology of mental health organizations. For example, mental health organizations may be required by licensing and funding agencies to hire professionals with particular credentials, to offer particular kinds of services and to evaluate their activities according to certain criteria.

Organizational adaptation varies along several dimensions including, for example, the extent to which changes in an organization involve core features (e.g., technology) or characteristics that are more peripheral (e.g., size of advisory board) and the time required for changes to occur (Hannan and Freeman, 1984). In our view, one of the most important adaptations of mental health organizations concerns adjustments they make in their staff or personnel patterns. The importance of personnel changes is that professionals and others in the field of mental health bring with them to organizations certain well-developed ideologies and beliefs concerning the cuases of and treatment for mental health problems. In other words, requirements to hire staff members with particular educational training may lead to changes in organizational ideology. In turn, the ideology of the dominant coalition in mental health organizations may play a key role in the selection and use of treatment approaches (Hasenfeld, 1983). Over the years, of course, various professional groups, including psychiatrists, psychologists, and social workers, have attempted to protect their interests in the mental health field by influencing licensing and funding agencies to establish staffing criteria that are favorable to their members.

In short, the adaptation of mental health organizations to rules established by powerful interest groups and organizations in their environment is likely to have consequences for several key aspects of 
their work, particularly their interaction with clients. Before we describe our approach to client-organization in more detail, we discuss variance in the adaptation of organizations.

\section{Failure to Adapt}

We introduced two assumptions concerning organization-environment relations. First, environments determine, to a significant extent, many important characteristics of mental health organizations. Second, mental health organizations can adapt to environmental contingencies and continue to perform their work over time. We want to elaborate our discussion of the second assumption somewhat by taking into account factors that prevent mental health organizations from adapting to environmental demands.

There are at least two broad classes of reasons for failure to adapt. One, as noted above, concerns "bounded rationality": That is, managers have limited perceptual and information processing systems. As a consequence, they may not have reliable and complete knowledge of their organizations' dependence on actors in the environment and they cannot respond appropriately. Weick's (1979) concept of "enacted environment" is also important here. Weick suggests that individuals create environments by processes of attention. Only that which is attended to can be "known." Further, attention itself is a limiting process. One cannot attend to multiple events simultaneously, and some events are necessarily excluded from observation. Thus, the limited ability of individuals to apprehend environments is an important cause for the failure of organizations to adapt.

A second class of reasons for organizations' failure to adapt has been suggested in work by population ecology theorists (e.g., Hannan and Freeman, 1977, 1984; Aldrich, 1979; McKelvey, 1982). These theorists have pointed out that organizations fail to change simply because they do not have the resources required by the environment or they cannot muster resources quickly enough. Hannan and Freeman (1984) pose questions such as, "How long does it take to obtain, process, and evaluate information on key environments?" "And how quickly can an organization be reorganized?" They argue that organizations fail when they cannot learn about their environments and change strategies and structures as quickly as their environments change. We are inclined to agree with them. 


\section{CLIENT-ORGANIZATION RELATIONS}

The third major focus of our conceptual framework concerns relationships between mental health organizations and their clients. $A$ key assumption of our framework is that client relationships with organizations are heavily influenced by the way organizations adapt to environments. In other words, the structures, technologies, and ideologies of mental health organizations that evolve in response to contingencies in the environment have consequences for the experiences of clients in organizations. We briefly discussed above, for example, a few implications that organizational adaptation in the area of personnel may have for the approaches to treatment available in mental health organizations. That is, the staff members of mental health organizations have strong preferences and values regarding treatment approaches, and they bring these ideologies to organizations that, in turn, significantly influence the experience of clients in treatment. In short, we are describing a series of linkages between events in the environment of mental health organizations, their pattern of adaptation, and their relationships with clients.

\section{The Client Career}

We agree with Hasenfeld (1983) and others who conceive of client's interaction with mental health organizations as a "career" unfolding in stages that are influenced by several important characteristics of both the organization and client. In our view, previous research has focused too narrowly on the effects of particular treatment approaches, neglecting the organizational context in which the treatment occurs. Our conceptual framework also assumes that the career of clients is heavily determined by the extent to which they are dependent on the organization (Hasenfeld, 1983). Mental health organizations typically hold a power advantage over clients, particularly clients of lower socioeconomic status who cannot mobilize the resources necessary to seek alternative sources of treatment.

The career of the client begins with the pathway by which he or she enters a mental health organization. For example, entry into treatment can be mandated or voluntary. After entry into an organization, the career continues with assessment and diagnosis that may result in matching clients to particular services and staff members. Then, the clients receive one or more of several treatment approaches. Finally, the client career closes with the client's exit from the organization. Of 
course, clients exit from mental health organizations in several ways. Some terminate treatment before its completion, while others terminate after a period of a few years, and still others are referred to other service organizations.

\section{THE EMPIRICAL CONTEXT}

The empirical research project that illustrates the use of our framework is a study of the organization of outpatient drug abuse treatment in the United States. The primary objective of the study is to explore the potential of the community mental health system to deliver drug abuse treatment on an outpatient basis. We are in the process of conducting a national comparative study of outpatient drug abuse treatment services in both the community mental health system and in community-based programs. We are focusing on the relationships between organizational environments, their adaptations, and clientorganization relations in three contexts in which outpatient drug abuse treatment may be delivered. They are (1) outpatient drug abuse services delivered outside the community mental health system (non-CMHC service); (2) services delivered as part of the array of treatment services available in community mental health centers ("hybrid" services); and, finally, (3) community mental health services that have no formal arrangements to deliver drug abuse treatment but that may encounter clients in need of treatment and may be considering the possibility of developing such services in the context of their organizations (CMHCs).

From a policy perspective, a primary interest of this study is in the appropriateness of the community mental health system to deliver outpatient drug abuse treatment. National Institute for Drug Abuse researchers (1978) reported that an increasing number of community mental health centers have become the organizational base for the delivery of outpatient drug abuse treatment services. However, little is known about the reasons for this development. Both the incentives and the barriers to the development of such services remain largely unexplored. Furthermore, questions about the effect of such an organizational evolution on the quality and kind of treatment services available remain largely unanswered.

This shift in organizational arrangements for the delivery of outpatient drug abuse programs in the community mental health system raises a number of questions for policymakers. For example, will drug abuse clients receive comparable services in the community mental 
health system? Do mental health personnel have the expertise to deliver such services, or will training or hiring initiatives be required? Policy questions regarding the costs of services in the community mental health system might also be raised.

From a theoretical point of view, however, the development of outpatient drug abuse services in the community mental health system may be thought of as an instance of organizational adaptation in which opportunities and/or demands in the environment of the community mental health system, such as new funding sources or new licensing requirements, lead to organizational adaptations such as the development of an outpatient drug abuse service with unknown effects on client-organization relations in general and on the career of drug abuse clients in particular. The data from our study provide the opportunity to test hypotheses about the relationships between environmental demands and opportunities and organizational adaptations, and, similarly, about relationships between the impact of organizational adaptations and client-organization relations.

Let us now turn to a brief consideration of the kinds of research questions that can be asked in this empirical context. Our questions are, of course, informed by the theoretical framework that we described earlier. One set of questions that we can consider involves the relationship between changes in the resource environment of community mental health centers and outpatient drug abuse treatment programs that may elicit a variety of forms of organizational adaptation. For example, do increases or decreases in the level of funding alter the pattern of hiring for treatment personnel so that organizations become increasingly professionalized or come to rely increasingly on less expensive paraprofessionals for treatment? Similarly, one may ask whether changes in requirements for third-party reimbursement might produce changes in the organization's screening and psychological testing procedures.

At still another level, we may examine the relationships between patterns of organizational adaptation and the effect of these adaptations on client-organization relations. For example, does an increase in professionalization of treatment staff produce a subsequent shift in treatment goals and/or the type of treatment technology provided?

\section{RESEARCH METHODOLOGY AND PRELIMINARY RESULTS}

Here we provide an overview of our research methods and a few preliminary results from the study. Our purpose is to provide further 
illustration of the conceptual framework presented above. The results are preliminary in that they are based on bivariate analyses of an incomplete sample of organizations; multivariate analyses on a complete set of data are now being conducted.

\section{RESEARCH DESIGN}

The research design for the study is presented in the matrix depicted in Table 2. One axis of the matrix shows the research phase of data collection, while the other axis shows the content area of the data that are being collected. The content areas or variables of interest are derived from the conceptual framework introduced earlier. More specifically, we are gathering data about (1) the environment of organizations in the study; (2) characteristics of their adaptation to the environment, including several aspects of the organization of treatment; and (3) characteristics of client-organization relations in the client career. Examples of variables in these areas of interest are listed in the Table 2.

SOME PRELIMINARY RESULTS:

CORRELATES OF CHANGES IN

STAFFING PATTERNS

The results reported here are from analyses of the correlates of staffing changes in $\mathrm{CMHC}$ and non-CMHC substance abuse treatment units. As noted above, changes in staffing patterns may be one important aspect of organizational adaptation to the environment that has implications for client-organization relations. Bivariate correlational analyses were conducted to determine the extent to which changes in funding are associated with changes in the pattern of staffing in the treatment units. All respondents who reported either adding or dropping professionals or paraprofessionals from their clinical staff in the past year were asked to indicate if the changes in staff were due to changes in funding.

The results suggest that CMHCs and non-CMHC organizations respond somewhat differently to changes in funding. Increases in funding for non-CMHC units are related to the addition of professional treatment staff. In contrast, $\mathrm{CMHCs}$ are not likely to attribute changes in personnel to increases in funding. At the same time, the data suggest that both $\mathrm{CMHC}$ and non-CMHC units attribute reduction in the number of professionals to decreases in funding. 


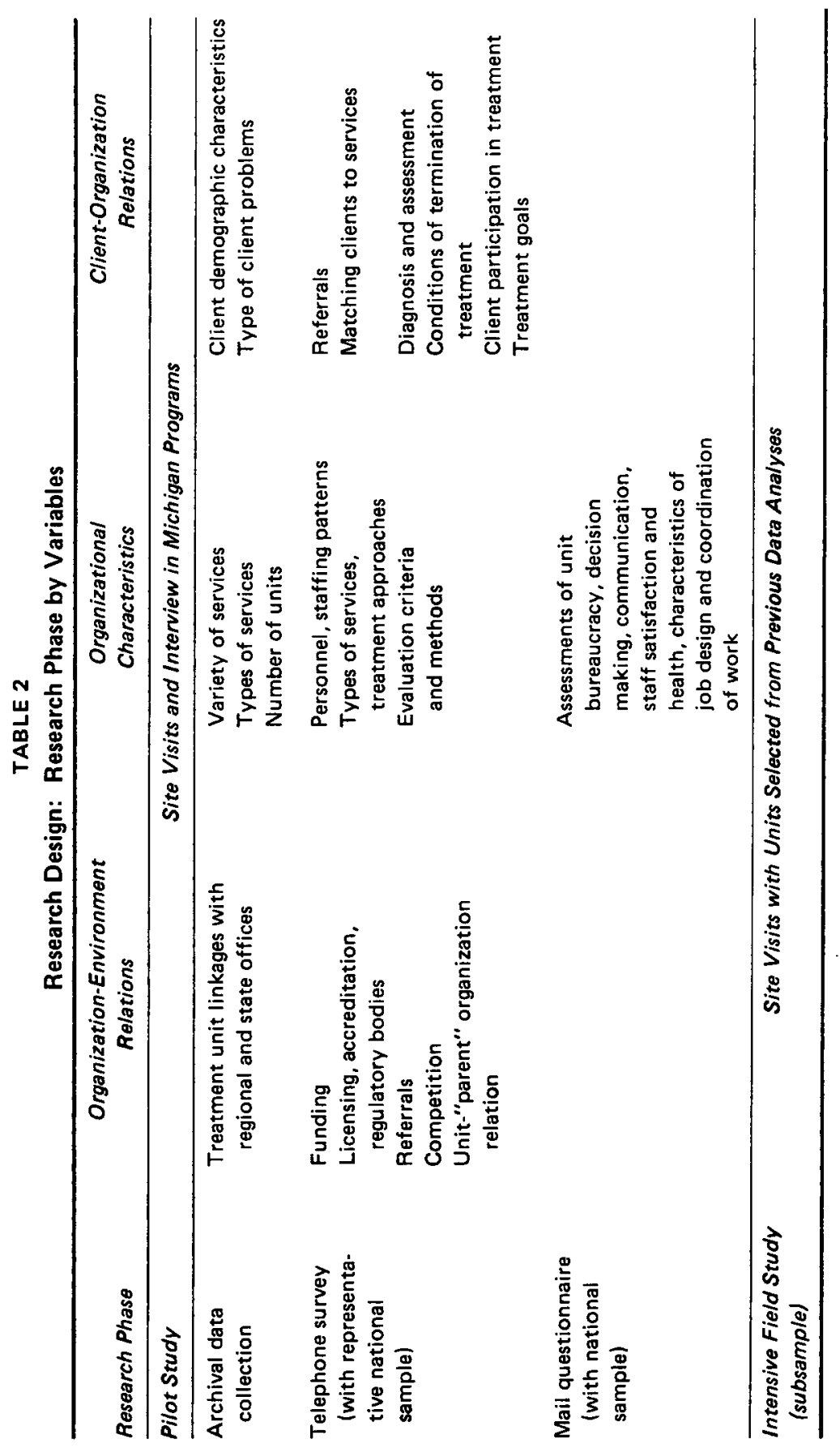


Taken together, the results suggest that personnel changes in both CMHC and non-CMHC units are influenced by changes in their funding environment. Further, when more funds are made available to non-CMHC units, they hire professionals. Both CMHC and nonCMHC units are more likely to drop professionals when funding decreases.

Next, we considered how changes in unit staffing, attributed at least in part to forces in the environment, might be related to treatment approaches used by the units. We found that CMHCs that add professionals or paraprofessional staff have a lower emphasis on client participation in treatment goal setting. In addition, for CMHCs a reduction in professional staff is associated with greater emphasis on client participation in treatment goals. In CMHCs staff reductions in general appear to be associated with an emphasis on complete abstinence from drinking or the use of other substances as a treatment goal. In non-CMHCs, however, reductions in paraprofessional staff are associated with a lower emphasis on sobriety and abstinence.

In short, the results suggest that changes in the environment of service organizations (e.g., changes in funding) are associated with changes in the organizations themselves (e.g., staffing patterns) that, in turn, may influence the treatment of clients (e.g., emphasis on different treatment goals). Bivariate analyses indicate that changes in funding for nonCMHC units were particularly likely to be related to changes in staffing patterns. Changes in staffing patterns for both non-CMHC and CMHC units were associated with emphasis on certain treatment goals as opposed to others. Clearly, however, much more work needs to be done to develop our understanding of the complex relationships between environmental forces, organizational adaptation, and client-organization relations.

\section{CONCLUSIONS}

We have described the conceptual framework, methodology, and a few preliminary findings of a national study of drug abuse treatment in the community mental health system. We offer this project as a case study of one approach to conducting research on mental health organizations. Let us briefly consider some theoretical and policy implications of our approach.

We believe that theory-based research can be useful to policymakers and that research stimulated by policy concerns can lend itself to 
answering basic theoretical questions. The organizational theorist may ask, What in the environment of mental health organizations stimulates the development of joint ventures, mergers, and other forms of "hybrid" treatment systems? Is it scarcity of resources in the environment? Or can it be explained as the product of especially entrepreneurial managers of mental health centers? Questions about the environment of the mental health organization may look somewhat different when posed by policymakers. For example, they may ask about the ability of new funding configurations or new licensing requirements to stimulate or inhibit the incorporation of outpatient drug abuse services or other new services within the community mental health system.

Organizational theorists and policymakers may also ask somewhat different questions of the same data when considering processes of organizational adaptation. For example, organizational theorists may be concerned with discovering the consequences for organizations that are involved in multiple systems of control. Is it the case, for example, that community mental health centers with drug abuse services that participate in two or more funding and licensing structures find this multiple participation to be a constraint on adaptation or an advantage because of diversification of resources and organizational ties? The policymaker on the other hand may be concerned about whether participation and multiple funding and licensing systems will involve overlap in services and funding with consequent inefficient resource utilization. The alternative possibility is, of course, that combined services actually complement and reinforce each other, producing improvements in the quality and availability of care.

We expect that the future of mental health organizations will be characterized by increasing complexity both in their environments and in the diverse patterns of adaptation they display. We think our approach to research on organizational adaptation may be helpful in understanding that complexity.

\section{REFERENCES}

ALDRICH, H.E. (1979) Environments and Organizations. Englewood Cliffs, NJ: Prentice-Hall.

BLAU, P.M. (1964) Exchange and Power in Social Life. New York: John Wiley.

BURT, R.S. (1980) “Models of network structure." Annual Rev. of Sociology 6: 79-141.

COOK, K.S. (1977) "Exchange and power in networks of interorganizational relations."

Sociological Q. 18 (Winter) 1: 62-82. 
EMERSON, R.M. (1962) “Power-dependence relations." Amer. Soc. Rev. 27: 31-41.

EVAN, W.M. (1966) "The organization set: toward a theory of interorganizational relations," pp. 173-188 in J.D. Thompson (ed.) Approaches to Organizational Design. Pittsburgh, PA: Univ. of Pittsburgh Press.

HALL, R.H. (1977) Organizations: Structure and Process. Englewood Cliffs, NJ: Prentice-Hall.

HANNAN, M. and J. FREEMAN (1984) "Structural inertia and organizational change." Amer. Soc. Rev. 49: 149-164.

_- (1977) "The population ecology of organizations." Amer. J. of Sociology 82: 929-964.

HASENFELD, Y. (1983) Human Service Organizations. Englewood Cliffs, NJ: Prentice-Hall.

___ (1972) "People-processing organizations: an exchange approach." Amer. Soc. Rev. 37: 256-263.

JACOBS, D. (1974) "Dependency and vulnerability: An exchange approach to the control of organizations." Admin. Sci. Q. 19: 45-59.

MARCH, J.G. and H.A. SIMON (1958) Organizations. New York: John Wiley.

McKELVEY, B. (1982) Organizational Systematics. Berkeley: Univ. of California Press.

——-and H.E. ALDRICH (1983) "Populations, natural selection, and applied organizational science." Admin. Sci. Q. 28: 101-128.

MEYER, J.W. and B. ROWAN (1977) "Institutionalized organizations: Formal structure as myth and ceremony." Amer. J. of Sociology 83 (September): 340-363.

MEYER, J.W. and W. R. SCOTT (1983) Organizational Environments: Ritual and Rationality. Beverly Hills, CA: Sage.

National Institute for Drug Abuse (1978) "The role of mental health center units in the drug abuse treatment delivery network." Rockville, MD: National Institute of Mental Health.

PFEFFER, J. and G.R. SALANCIK (1978) The External Control of Organizations: A Resource Dependence Perspective. New York: Harper \& Row.

SCOTT, W. R. (1983) "Health care organizations in the 1980s: The covergence of public and professional control systems." pp. 99-114 in J.W. Meyer and W. R. Scott (eds.) Organizational Environments: Ritual and Rationality. Beverly Hills, CA: Sage.

-_- and J. W. MEYER (1983) "The organization of societal sectors," pp. 129-154 in J. W. Meyer and W. R. Scott (eds.) Organizational Environments: Ritual and Rationality. Beverly Hills, CA: Sage.

THOMPSON, J.D. (1967) Organizations in Action. New York: McGraw-Hill.

WAMSLEY, G.L. and M.N. ZALD (1976) The Political Economy of Public Organizations. Bloomington: Indiana Univ. Press.

WARREN, R.L. (1972) The Community in America. Chicago: Rand McNally.

-__ (1967) "The interorganizational field as a focus for investigation." Admin. Sci. Q. 12 (December): 396-419.

WEICK, K.E. (1979) The Social Psychology of Organizing. Reading, MA: Addison-Wesley.

WILLIAMSON, O.E. (1981) "The economics of organization: The transaction-cost approach." Amer. J. of Sociology 87: 548-577.

and W.G. OUCHI (1981) "The markets and hierarchies and visible hand perspectives: The markets and hierarchies program of research: Origins, implications, prospects," in A. Van de Ven and J. Joyce (eds.) Perspectives on Organization Design and Behavior. New York: John Wiley. 